\title{
A Influência da Marca e de seus Atributos na Escolha de Cosméticos: um Estudo Experimental
}

\section{The Influence of Brand Attributes on Cosmetics Choice: an Experimental Study}

\author{
Francyele Silva Rocha ${ }^{\mathrm{a}}$; Keila Aparecida Marques; ${ }^{\mathrm{b}}$ Simone Hilário da Silva Brasileiro ${ }^{\mathrm{b}}$; Sulamita da Silva Lucas; \\ Mirian Sousa Moreira ${ }^{a}$; André Vasconcelos da Silva ${ }^{a}$
}

${ }^{a}$ Universidade Federal de Goiás. GO, Brasil.

'Universidade Federal de Goiás, Programa de Pós-Graduação Stricto Sensu em Gestão Organizacional. GO, Brasil.

*E-mail: francyelesrocha@hotmail.com

\begin{abstract}
Resumo
Esta pesquisa realiza uma abordagem sobre a influência da marca e de seus atributos na escolha de cosméticos, proporcionando a oportunidade de análise de todo um conjunto de associações positivas ao produto, e a sua consequente aceitação por parte do público consumidor, que se traduz em resultados como: aceitação, satisfação e benefícios. O objetivo consiste em verificar o efeito do número de itens associados à marca de cosméticos na preferência de escolha, analisando se os reforços utilitários ou informativos podem influenciar na escolha da marca. O método de coleta de dados se trata de uma pesquisa de campo com os universitários de disciplinas eletivas, em que na primeira fase foi aplicado um questionário sociodemográfico para 66 alunos e, na segunda fase, 12 desses alunos responderam um questionário online. Foi utilizada a pesquisa bibliográfica e explicativa, abordando sobre marketing, comportamento do consumidor e o Modelo da Perspectiva Comportamental da Compra e Consumo (BPM). A análise sugeriu que a variável história de aprendizagem foi proeminente em ambos os grupos e fases do estudo, assim como as características na escolha das marcas são mais voltadas para reforços utilitários na escolha subsequente dos reforços informativos, e que o número de alternativas não teve grande relevância na escolha, sendo importante ressaltar que as experiências anteriores prevaleceram no momento da escolha.
\end{abstract}

Palavras-chave: Consumidor. Escolha. Marca.

\begin{abstract}
This research approaches the influence of the brand attributes on the cosmetics choice, providing an opportunity to analyze a whole set of positive associations of a product, and its consequent acceptance by the consumers, which translates the results related to acceptance, satisfaction and benefits. The objective is to verify the effect of items number associated with cosmetic brand in choice preference, analyzing whether utilitarian or informative reinforcements can influence the brand's choice. The data collection method was a field research with students. In the first phase, a socio-demographic questionnaire was applied to 66 students and in the second phase 12 of these students answered an online questionnaire. A bibliographic and explanatory research was used about marketing, consumer behavior and The Behavioral Perspective Model of Purchase and Consumption (BPM). The analysis suggested that learning history was prominent in both groups and phases of the study, as well as characteristics in brands choice are more focused on utilitatrian reinforcement than informative reinforcements. Number of alternatives did not show great importance in the choice, being important to emphasize that previous experiences prevailed at the moment of choice.
\end{abstract}

Keywords: Consumer. Choice. Brand.

\section{Introdução}

O consumidor do mercado atual está cada vez mais exigente e busca adquirir os produtos ou serviços prestados com muita qualidade. No caso dos cosméticos não é diferente, os consumidores têm ao seu alcance diversas marcas e estão prontos para fazer as suas escolhas, conforme o que há de melhor em cada marca oferecida (KOTLER,2003).

Como método será utilizada a pesquisa bibliográfica, abordando sobre marketing, comportamento do consumidor e o Modelo da Perspectiva Comportamental da Compra e Consumo (BPM). A pesquisa será explicativa, pois irá explicar os motivos que levam os universitários a escolher cosméticos e se a marca é a principal responsável por esta escolha. Será realizada ainda uma pesquisa de campo com os universitários de disciplinas eletivas.

Por meio desta pesquisa é possível tecer discussão sobre como determinadas empresas incorporam aos seus produtos as qualidades que enfatizem a relação da marca e seus valores com os consumidores (KOTLER,2003). Tratase, pois, de uma discussão também sobre como as marcas criam um vínculo emocional, e levam o público consumidor a manter fidelidade para com os produtos que consomem. Esta abordagem proporciona a oportunidade para que seja analisado todo um conjunto de associações positivas ao produto, e a sua consequente aceitação por parte do público consumidor, que se traduz em resultados como aceitação, satisfação e benefícios.

O objetivo consiste em verificar o efeito do número de itens associados à marca de cosméticos na preferência de escolha, analisando se os reforços utilitários ou informativos podem influenciar na escolha da marca.

Sendo assim, o posicionamento do consumidor frente aos produtos que consome constitui um processo, que implica em 
um relacionamento com as marcas construído ao longo de um tempo. Trata-se de um processo de persuasão contínua, para encorajar o cliente a pensar de uma determinada maneira, levando-o a consumir cada vez mais o produto que lhe é oferecido, através de propagandas persuasivas.

\section{Material e Métodos}

\subsection{Participantes}

O presente estudo foi desenvolvido em duas fases, para a fase 1 participaram sessenta e seis alunos de diversos cursos de uma Universidade Federal de Goiás - Regional Catalão, sendo 40 femininas e 26 masculinas, com idade variando entre 17 a 41 anos.

Das quais 12 pessoas, de ambos os sexos, seguiram para a fase 2. Sem experiência anterior em pesquisas de comportamento de escolha participaram do experimento.

\subsection{Coleta de dados}

Para a realização desta pesquisa foram utilizados um questionário sociodemográfico do padrão de compra e um questionário online desenvolvido utilizando a plataforma do site surveymonkey.com, em que foi apresentado uma Sequência Experimental.

A fase 1 consistiu na aplicação do questionário sociodemográfico. A coleta de dados foi realizada de forma coletiva disponibilizado em aula, de uma Universidade Pública.

A fase 2 consistiu em um jogo de comportamento de escolha. Para o início da coleta de dados, foi feita uma reunião com os participantes, na qual houve a explicação sobre a pesquisa e a separação dos grupos.

Os participantes foram divididos em quatro grupos: Grupo 1, 2 e 4 sem acesso ao grupo do facebook; Grupo 3 com acesso ao grupo no facebook. Já para o grupo 3 foram enviados os e-mails com uma sequência na medida em que respondiam e emitiam curtidas ou comentários nas publicações no grupo do facebook. Os e-mails foram enviados aos participantes cadastrados e foram analisados os dados recebidos.

Os questionários apresentavam na primeira tela a Instrução Geral. Após sua leitura havia uma tela que os participantes indicaram os dados gerais de nome, de idade, de sexo e de curso. Logo em seguida, começava a sequência com estímulos de dois elos: elo inicial e elo secundário. Após o elo secundário retornava ao elo inicial, o indivíduo foi exposto a quarenta tentativas. A cada cinco tentativas era apresentado ao indivíduo uma tela solicitando o seu relato, para saber qual seu critério de escolha. A cada dez tentativas, o indivíduo respondia o questionário de valor percebido, identificando qual valor o indivíduo estaria disposto a pagar pelo produto. No final das 40 tentativas, o indivíduo respondia o questionário de histórico de compra. Conforme esquema da Figura 1.
Figura 1 - Esquema do delineamento experimental

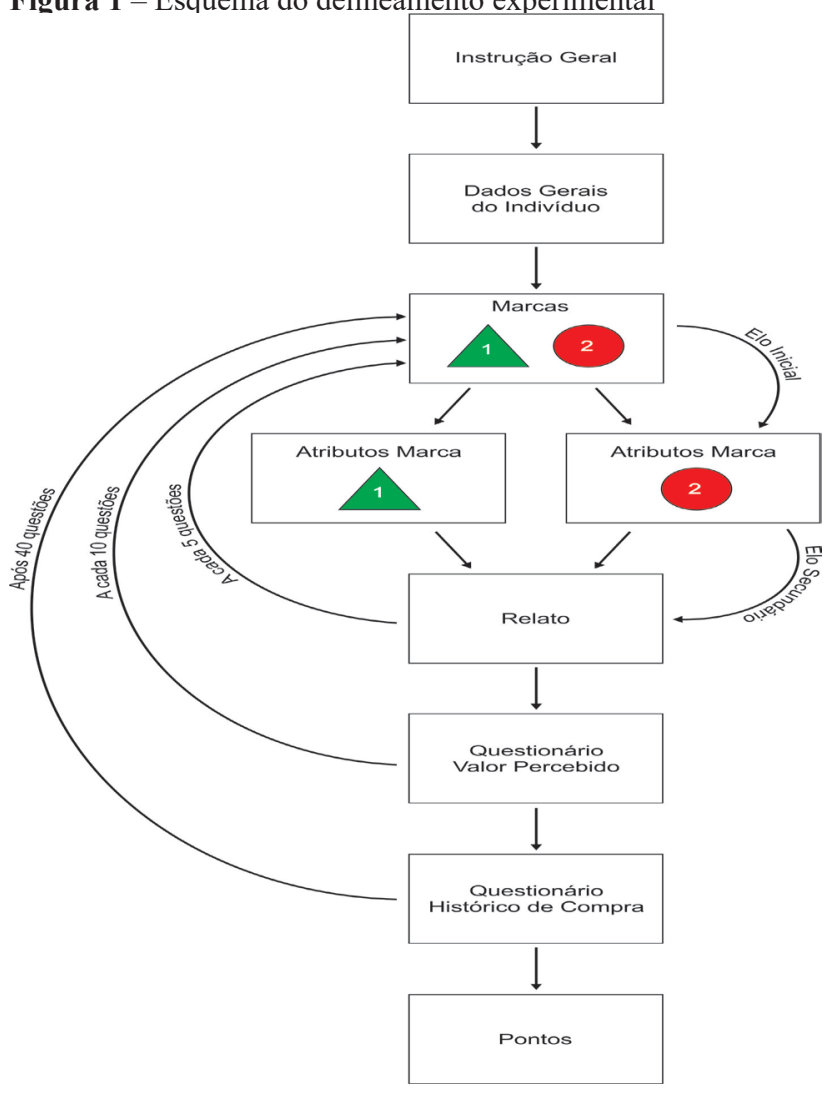

Fonte: Os autores

No elo inicial eram apresentadas duas marcas de categoria de produtos, ao escolher uma marca, seguia para o elo secundário o qual continha atributos. $\mathrm{O}$ elo secundário variou de acordo com o grupo experimental que o participante foi submetido. Foram apresentados três tipos de elos secundários: com um atributo; dois atributos e quatro atributos. Esses atributos podiam ser com reforços utilitários ou reforços informativos (Quadro 1).

Quadro 1 - Divisão de atributos por grupo

\begin{tabular}{|c|c|}
\hline Grupo 1 & $\begin{array}{c}\text { Dois atributos utilitários } \\
\text { Quatro atributos informativos }\end{array}$ \\
\hline Grupo 2 & $\begin{array}{c}\text { Dois atributos informativos } \\
\text { Quatro atributos utilitários }\end{array}$ \\
\hline Grupo 3 & $\begin{array}{c}\text { Um atributo informativo } \\
\text { Quatro atributos informativos }\end{array}$ \\
\hline Grupo 4 & $\begin{array}{c}\text { Um atributo utilitário } \\
\text { Quatro atributos utilitários }\end{array}$ \\
\hline
\end{tabular}

Fonte: dados da pesquisa.

No elo primário foram apresentados cinco produtos: creme dental (a), sabonete (b), desodorante (c), batom (d) e creme de barbear (e), cujas marcas estão descritas no Quadro abaixo. Foram apresentados os produtos "a", "b" e "c" para todos. Quando do gênero feminino se apresentava o produto "d", quando masculino se apresentava o produto "e". As marcas dos produtos apresentadas no Quadro 2, que compõem esta pesquisa foram selecionadas, com base em uma matéria de uma revista, que aplicou uma pesquisa sobre a preferência de marcas de cosméticos na opinião dos brasileiros. Esses produtos foram apresentados de forma randomizada, cada 
um dos quatro produtos foi apresentado dez vezes e a ordem de apresentação também foi randomizada. O conjunto destas apresentações formavam uma sequência e o conjunto de oito sequências, que formavam um grupo.

Quadro 2-Marcas utilizadas no experimento

\begin{tabular}{|c|c|}
\hline Produtos & Marcas \\
\hline Creme dental & Colgate e Oral B \\
\hline Sabonete & Protex e Dove \\
\hline Desodorante & Dove e Rexona \\
\hline Creme de barbear & Bozzano e Gillette \\
\hline Batom & Natura e O Boticário \\
\hline
\end{tabular}

Fonte: dados da pesquisa.
Em cada sequência, o participante ganhava pontos. A obtenção dos pontos dependia do esquema programado para as condições experimentais. Os participantes foram submetidos às seis condições experimentais: duas linhas de base $(0,0)$, e duas para cada um dos esquemas programados. O Quadro 3 apresenta as sequências probabilísticas de reforçamento programadas para as condições experimentais. Cada sessão experimental consistia em 40 tentativas. Ao final, aparecia uma tela com a mensagem indicando a pontuação obtida por cada participante.

Quadro 3 - Sequência dos esquemas probabilísticos de reforçamento utilizados nas sessões

\begin{tabular}{|c|c|c|c|c|c|c|}
\hline Sequência & Condição 1 & Condição 2 & Condição 3 & Condição 4 & Condição 5 & Condição 6 \\
\hline 1 & 0,0 & 0,0 & 0,0 & 0,0 & 0,0 & 0,0 \\
\hline 2 & 0,10 & 0,10 & 0,50 & 0,50 & 0,90 & 0,90 \\
\hline 3 & 0,10 & 0,10 & 0,50 & 0,50 & 0,90 & 0,90 \\
\hline 4 & 0,50 & 0,90 & 0,10 & 0,90 & 0,10 & 0,50 \\
\hline 5 & 0,50 & 0,90 & 0,10 & 0,90 & 0,10 & 0,50 \\
\hline 6 & 0,90 & 0,50 & 0,90 & 0,10 & 0,50 & 0,10 \\
\hline 7 & 0,90 & 0,50 & 0,90 & 0,10 & 0,50 & 0,10 \\
\hline 8 & 0,0 & 0,0 & 0,0 & 0,0 & 0,0 & 0,0 \\
\hline
\end{tabular}

Fonte: dados da pesquisa.

Para coletar, dar confiabilidade aos dados e garantir a jogabilidade inspirada no modelo de Foxall (1990), era imprescindível a disposição de mais de uma categoria de produtos, pois isso garantiria uma maior randomização dos dados. Entretanto, para analisar os resultados coletados foi selecionada aleatoriamente a categoria de produtos "creme dental". Diante disso, os resultados, a discussão e as considerações finais desta pesquisa foram embasados apenas nesta categoria em questão.

\section{Resultados e Discussão}

\subsection{Informações quanto à utilização dos produtos}

Buscou-se identificar nesta pesquisa alguns produtos que os participantes utilizam, ou seja, se são produtos que eles têm o hábito de usar. Obtiveram-se os seguintes dados sobre os produtos que os participantes da pesquisa usam para proteger a pele, ou seja, protetor solar, faz uso desses $76 \%$ e não usam o protetor $24 \%$. Nesta mesma linha de raciocínio, foi perguntado ao participante desta pesquisa se utiliza algum produto para cuidar dos dentes, $100 \%$ responderam que sim.

Ainda, sobre os produtos que utilizam, $98 \%$ responderam que fazem uso de perfumes e $2 \%$ responderam que não usam. Quanto ao uso de desodorantes, $100 \%$ responderam que usam desodorantes.

Os dados apresentaram que 95\% dos participantes da pesquisa usam produtos para o cabelo e 5\% não usam. Quanto ao uso do sabonete, 100\% responderam usar. Quanto à utilização dos produtos para a barba $32 \%$ usam e $68 \%$ não usam. Em relação aos produtos para o rosto, $70 \%$ usam e $30 \%$ não usam.

Sobre os cuidados com o corpo, $74 \%$ responderam que fazem uso de produtos e $26 \%$ responderam não usar nada. Quanto ao uso de maquiagem, 56\% fazem uso e 44\% não usam nada. Quanto à utilização de produtos para cuidados com as unhas, $65 \%$ responderam fazer uso de produtos e $35 \%$ não usam nada.

\subsection{Frequência de uso}

Esta mesma pesquisa também procurou verificar com que frequência os participantes fazem uso de alguns produtos que disseram usar. Em se tratando da frequência de uso do protetor solar, $52 \%$ responderam ser diariamente, $30 \%$ semanalmente, $2 \%$ quinzenalmente e $16 \%$ mensalmente. Já o cuidado com os dentes as respostas foram, 100\% diariamente.

Em relação ao uso de perfumes, $79 \%$ responderam ser diariamente, $15 \%$ semanalmente e $6 \%$ diariamente. Quanto ao desodorante, $100 \%$ utilizam diariamente. Em se tratando da frequência que utilizam produtos para o cabelo, $78 \%$ responderam que diariamente e 22\% semanalmente. Quanto ao uso de sabonetes a frequência foi de $100 \%$ diariamente.

Sobre a frequência que utilizam produtos para a barba, $19 \%$ responderam ser diariamente, $43 \%$ semanalmente, $14 \%$ quinzenalmente, $19 \%$ mensalmente e $5 \%$ diariamente. A propósito dos cuidados com o corpo, 78\% fazem uso diariamente, $20 \%$ semanalmente, $2 \%$ semanalmente. Quanto à frequência de uso de maquiagem, 54\% responderam ser diariamente, $40 \%$ semanalmente e $3 \%$ quando fazem uso de alguma atividade.

Nos cuidados com as unhas, a frequência acontece da 
seguinte forma: $12 \%$ diariamente, $51 \%$ semanalmente, $26 \%$ quinzenalmente, $9 \%$ mensalmente e $2 \%$ quando desenvolve algum tipo de atividade.

\subsection{Qual marca utiliza}

$\mathrm{Na}$ pesquisa proposta também se procurou obter conhecimento sobre as marcas que os participantes da pesquisa utilizam, em se tratando de protetor, $85 \%$ usam Avon, 18\% usam Sundown, 4\% Natura, 12 Nívea, 46\% outra marca e $12 \%$ compra qualquer marca.

As marcas utilizadas para cuidar dos dentes são: $67 \%$ Colgate, $7 \%$ Oral B, 9\% Listerine, 3\% outra marca e 14\% não faz distinção. As marcas mais utilizadas de perfumes são: o Boticário com $42 \%$, importados $30 \%$, Natura 3\%, outras 5\% e não faz distinção $20 \%$.

As marcas mais utilizadas nos cabelos são: Clear 10\%, Seda $8 \%$, Dove 3\%, Elseve 3\%, Pantene 19\%, Tressemme $11 \%$, outra marca $21 \%$ e não fazem distinção $25 \%$. Ainda se procurou conhecer as marcas mais usadas de desodorantes, 39\% usam Rexona, 21\% Dove, 9\% Nívea, outra marca 20\% e não faz distinção $11 \%$.

As marcas de sabonetes mais usadas são: Protex 20\%, Dove $33 \%$, Natura $9 \%$, outra marca $24 \%$ e não faz distinção $14 \%$. Quanto aos produtos de barba mais utilizados são: Gillette $29 \%$, Bozzano $24 \%$, Nivea $5 \%$, outra marca $9 \%$ e não faz distinção $33 \%$.

Em se tratando das marcas dos produtos utilizados no rosto, a Avon 6\%, Natura 9\%, Mary Kay 24\%, outra marca $35 \%$ e não faz distinção $26 \%$. Referentes aos cuidados com o corpo, os produtos mais usados foram: Natura 31\%, O Boticário $37 \%$, Avon $6 \%$, outra marca $8 \%$ e não faz distinção $18 \%$.

Sobre as marcas mais usadas de maquiagem, Natura $14 \%, 16 \%$ O Boticário, Avon 8\%, outra marca $27 \%$ e não faz distinção $35 \%$. Em relação aos cuidados com as unhas, os consumidores também têm preferências de marcas, sendo: Risque $46 \%$, Colorama $9 \%$, outra marca $5 \%$ e sem distinção $40 \%$.

\subsection{Quem compra}

A compra do protetor solar é realizada pelos pais $24 \%$, pelo companheiro (a) $2 \%$, pelo respondente $66 \%$, não responderam $6 \%$. Quanto à compra de perfumes $12 \%$ pelos pais, $2 \%$ pelo marido / esposa, $81 \%$ pelo respondente, $5 \%$ por outra pessoa.

A compra do desodorante é realizada da seguinte forma: pelos pais $17 \%$, pelo marido/esposa $1 \%$, pelo próprio respondente $77 \%$ e por outra pessoa $5 \%$. Os produtos para o cabelo ficaram da seguinte forma: pelos pais $27 \%$, pelo companheiro (a) $1 \%$, pelo marido ou esposa $2 \%$, pelo respondente $68 \%$, por outra pessoa $2 \%$.

A compra do sabonete é realizada: pelos pais 33\%, pelo marido ou esposa $2 \%$, pelo próprio respondente $59 \%$, por outra pessoa $3 \%$ e sem respostas $3 \%$. Os produtos para a barba ficaram da seguinte forma: pelos respondentes $76 \%$, pelos pais $10 \%$ e sem respostas $14 \%$.

Em se tratando de produtos para o rosto, a compra é efetuada por: pais $13 \%$, pelo respondente $80 \%$, sem respostas $7 \%$. Para produtos relacionados ao cuidado com o corpo, a aquisição é feita por: pais $16 \%$, pelo marido ou esposa $2 \%$, pelo respondente $76 \%$, sem respostas $6 \%$.

A compra da maquiagem ficou da seguinte forma: pelos pais $11 \%$, marido ou esposa $3 \%$, pelo respondente $86 \%$. Os produtos para cuidados com as unhas, pelos pais $14 \%$, pelo marido ou esposa $5 \%$, pelo respondente $70 \%$, sem respostas $11 \%$.

Os produtos para cuidar dos dentes são adquiridos da seguinte forma: pelos pais $40 \%$, marido ou esposa $2 \%$, pelo respondente $56 \%, 2 \%$ outra pessoa.

\subsection{Características que Influenciam a Compra}

Sobre as características se têm os seguintes dados, segundo a opinião dos participantes da pesquisa.

Os participantes da pesquisa responderam que o protetor solar quanto as suas características apresentaram as seguintes respostas: qualidade $14 \%$, preço $20 \%$, fator solar $16 \%$, marca $10 \%$, quantidade $10 \%$, fragrância $6 \%$, cor $3 \%$, textura $4 \%$, proteção $3 \%$, tipo de pele $9 \%$ e benefícios $5 \%$.

Em se tratando dos cuidados com os dentes, os participantes responderam que adquirem conforme as seguintes características: $22 \%$ preço, $15 \%$ qualidade, $12 \%$ marca, $10 \%$ sabores, $4 \%$ refrescância, $6 \%$ quantidade, $1 \%$ cores, $2 \%$ experiência anterior, $13 \%$ benefícios, $4 \%$ clareador, $3 \%$ embalagem, $5 \%$ proteção e $3 \%$ para dentes sensíveis.

Buscando conhecer sobre as características dos desodorantes no processo de compra, as características determinantes foram: $20 \%$ preço, $14 \%$ qualidade, $3 \%$ eficácia, 7\% marca, 23\% fragrância, 3\% antitranspirante, $6 \%$ quantidade, $6 \%$ proteção, $9 \%$ durabilidade, $3 \%$ não mancha a roupa e $6 \%$ embalagem.

As características dos produtos para cabelo foram: $21 \%$ fragrância, $19 \%$ qualidade, $20 \%$ preço, $5 \%$ marca, $6 \%$ quantidade, $3 \%$ embalagem, $3 \%$ hidratação e $9 \%$ tipo de cabelo.

Quanto às características dos perfumes, ficaram da seguinte forma: $31 \%$ fragrância, 13\% qualidade, $21 \%$ preço, $10 \%$ marca, $8 \%$ durabilidade, $9 \%$ quantidade, $3 \%$ embalagem, $2 \%$ fixação, $1 \%$ indicação e $2 \%$ confiabilidade.

Sobre as características dos sabonetes, os participantes da pesquisa responderam: 13\% qualidade, 24\% preço, 29\% fragrância, 8\% marca, 4\% antibacteriano, 1\% cor, 5\% quantidade, $12 \%$ benefícios e $4 \%$ hidratação.

Em se tratando dos produtos para a barba, as características ficaram da seguinte forma: $17 \%$ qualidade, $29 \%$ preço, $14 \%$ marca, $8 \%$ fragrância, $6 \%$ eficiência e $26 \%$ benefícios.

Sobre as características dos produtos para o rosto, as características levadas em conta foram: $28 \%$ qualidade, $3 \%$ indicação, $10 \%$ marca, $22 \%$ preço, $8 \%$ fragrância e $29 \%$ benefícios. 
Em se tratando com os cuidados com o corpo, as características são: $14 \%$ qualidade, $23 \%$ preço, $24 \%$ fragrância, $16 \%$ benefícios, $5 \%$ marca, $6 \%$ quantidade, $6 \%$ textura, $3 \%$ durabilidade e $3 \%$ tipo de pele.

Sobre as características da maquiagem $25 \%$ responderam ser a qualidade, $23 \%$ preço, $8 \%$ marca, $3 \%$ indicação, $9 \%$ durabilidade, $4 \%$ fragrância, $8 \%$ textura e 20\% benefícios.

Em relação aos cuidados com as unhas, as características foram $24 \%$ qualidade, $10 \%$ marca, $25 \%$ preço, $23 \%$ cor, $10 \%$ durabilidade, 5\% hipoalergênico e 3\% textura.

As Figuras 2 e 3 se referem às preferências de escolhas dos 12 participantes, sendo 6 em cada grupo. Foram analisadas as respostas referentes ao produto creme dental.

Figura 2 - Preferência de Escolha do Grupo 1 (Colgate - 2 atributos utilitários e Oral B - 4 atributos informativos)
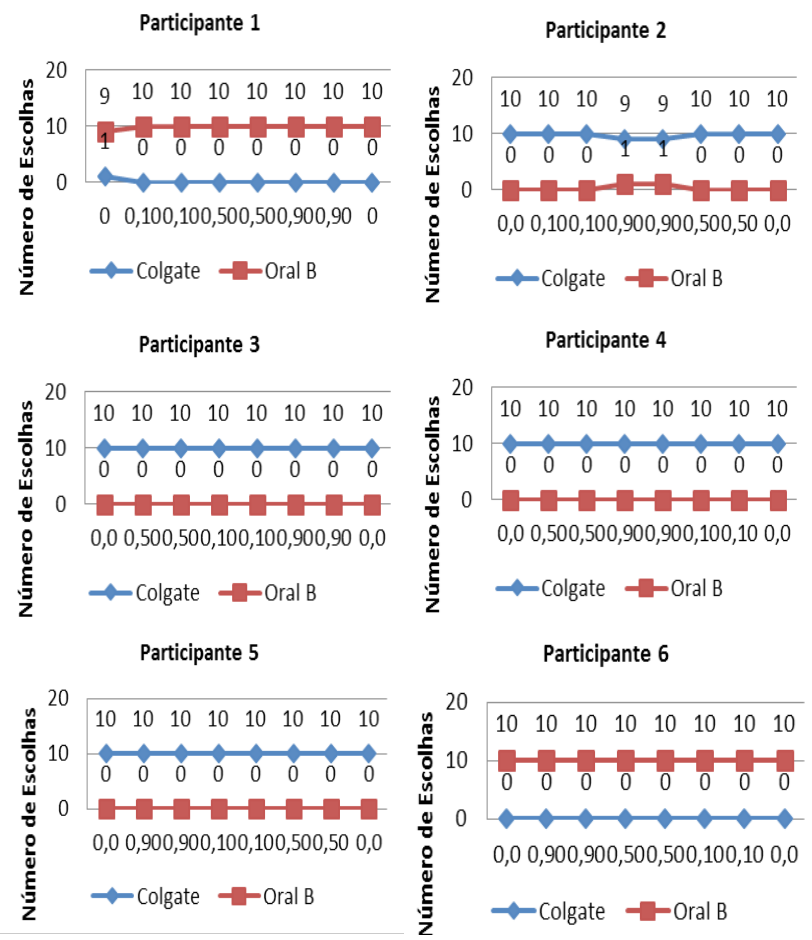

Fonte: Dados da pesquisa.

O Participante 1 , na primeira sequência $(0,0)$, demonstrou preferência pela marca Oral B 9 vezes e pela marca Colgate 1 vez. Nas demais sequências $(0,10 / 0,10 / 0,50 / 0,50 / 0,90 / 0,90 / 0$, 0 ) escolheu em todas as tentativas Oral B.

O participante 2 , em duas sequências $(0,90 / 0,90)$ optou 9 vezes por Colgate e 1 vez por Oral B. Nas outras sequências $(0,0 / 0,10 / 0,10 / 0,50 / 0,50 / 0,0)$ em todas as tentativas escolheu Colgate.

Os participantes 3,4 e 5 em todas as sequências demonstraram preferência pela marca Colgate. Enquanto o participante 6 optou por Oral B em todas as suas tentativas. Lembrando que no elo secundário, os atributos eram dois utilitários para Colgate e quatro informativos para Oral B.
Figura 3 - Preferência de Escolha do Grupo 2 (Colgate - 4 atributos utilitários e Oral B - 2 atributos informativos)

Participante 1

Participante 2
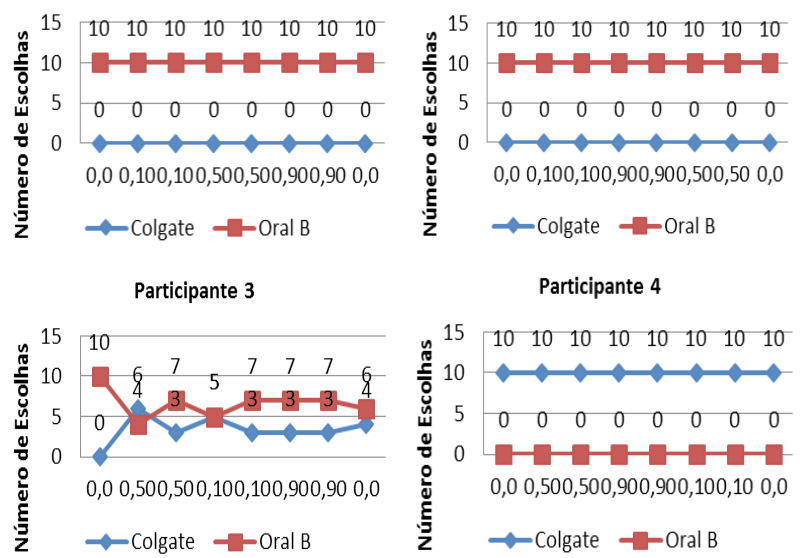

Participante 5

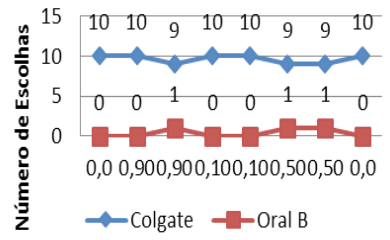

Participante 6

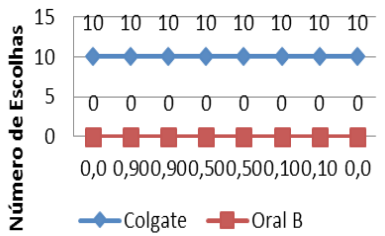

Fonte: Dados da pesquisa.

Os participantes 1 e 2 demonstraram preferência pela marca Oral B em todas as tentativas da sequência experimental. Enquanto, o participante 6 escolheu nas 8 sequências a marca Colgate.

O participante 3 , em sua primeira sequência $(0,0)$, escolheu Oral B. Nas sequências $(0,50 / 0,10 / 0,90 / 0,90)$ apontou Oral B 7 vezes e 3 vezes pela marca Colgate. Já na sequência $(0,50)$ escolheu 6 vezes Colgate e 4 vezes Oral B. Enquanto na última sequência $(0,0)$, optou 6 vezes por Oral B e 4 vezes por Colgate.

O participante 5, em cinco das sequências $(0,0 / 0,90 / 0,10 / 0,10 / 0,0)$, demonstrou preferência por Colgate e em 3 sequências $(0,90 / 0,50 / 0,50)$ escolheu 9 vezes Colgate e 1 vez Oral B. Neste grupo, os atributos eram quatro utilitários para Colgate e 2 atributos informativos para Oral B.

Todos os participantes foram convidados a escrever um relato a cada cinco tentativas informando o seu critério de escolha. Em relação ao que escreveram segue abaixo as análises:

Em relação ao Grupo 1: o participante 1 disse escolher os produtos com os quais já se identifica na compra. $\mathrm{O}$ participante 2 escreveu que o mais importante na compra é a tradição e a qualidade no mercado. O participante 3 descreveu que a qualidade, marca, fragrância e status foram os responsáveis pela escolha. $\mathrm{O}$ participante 4 disse ter escolhido produtos que já utiliza. O participante 5 escreveu escolher pela consistência, pelos resultados apresentados na descrição do produto, fragrância, preço, qualidade, tamanho e tipo. E o participante 6 disse que optou pelas marcas que já utiliza ou conhece. 
No grupo 2: o participante 1 escreveu que escolheu as marcas em função de sua qualidade e credibilidade no mercado. O participante 2 descreveu que procura produtos que tenham fácil utilização, instruções claras, odor agradável, que proteja de micro-organismos estranhos e seja um produto de confiança. O participante 3 disse escolher pela qualidade, valor, fragrância e afinidade com a marca. O participante 4 escreveu que optou por um produto que já utiliza. $\mathrm{O}$ participante 5 busca qualidade e fragrância do produto. $\mathrm{O}$ participante 6 disse que escolheu por ser uma marca que já está acostumado a comprar e não apresenta reações alérgicas.

\section{Conclusão}

Pode-se verificar, que os participantes do sexo feminino predominaram na pesquisa, sendo $61 \%$, e $56 \%$ disseram ter entre 17 e 21 anos. Quanto à utilização destes produtos se nota que fazem uso e conhecem estes produtos. A categoria produtos para barba foi a que apresentou menos utilização, $68 \%$ não utilizam e $32 \%$ utilizam, supõe-se que este dado seja em função de os respondentes serem predominantes do sexo feminino. Em relação a quem compra o produto se observa que em todas as categorias, geralmente, o próprio respondente é responsável por escolha e compra.

Considerando a pergunta "Qual marca você utiliza?" se verifica que as marcas mais utilizadas entre os respondentes são: na categoria protetor solar, sendo $46 \%$, optaram pela opção "outra marca" não escolhendo as marcas descritas no questionário. Sobre a categoria cuidados com os dentes, a marca que se destacou foi Colgate, com $67 \%$. Em relação aos perfumes, a marca foi O Boticário, que obteve $42 \%$. A respeito de produtos para cabelo, $25 \%$ disseram não fazer distinção de marcas na compra. Quanto à categoria de desodorantes, Rexona foi a marca mais apontada com 39\%. Já a categoria sabonete, a marca mais utilizada pelos respondentes foi Dove, com 33\%. Os respondentes que utilizam produtos para barba, $33 \%$ não fazem distinção na escolha da marca. Para a categoria produtos para o rosto, $35 \%$ dos respondentes optaram por outra marca. As respostas sobre a categoria cuidados com o corpo, a marca O Boticário é utilizada por $37 \%$ dos consumidores. Em relação à categoria maquiagem, $35 \%$ não fazem distinção de marcas. Sobre a categoria cuidados com as unhas $46 \%$ optaram pela marca Risque.

As características citadas pelos respondentes sobre o que consideram ao optar por produtos cosméticos foram: qualidade, preço, fragrância e marca. O que evidencia que eles já têm uma história de compra e o que pesa nesta escolha são características mais voltadas para reforços utilitários.

Verificou se que no grupo 1, de forma geral, que quatro participantes demonstraram preferência por Colgate e dois participantes escolheram Oral B. Quando se analisa o elo secundário deste grupo se nota que a marca Oral B era composta por quatro atributos informativos e Colgate por dois atributos utilitários. Percebe-se que o atributo utilitário foi mais relevante do que o informativo.
Já no Grupo 2, a preferência de escolha de três participantes foi a marca Colgate e os outros três apontaram o Oral B como marca de sua preferência. E ao observar o elo secundário se tem para Colgate quatro atributos utilitários e para Oral B dois atributos informativos.

Parece que os participantes são mais sensíveis a escolha em função do atributo utilitário do que ao informativo. Para estes participantes, os atributos utilitários têm mais importância do que os atributos informativos, conforme relataram como critério de escolha, seja a consistência, tamanho, tipo ou fragrância.

A variável de história de aprendizagem foi proeminente em ambos os grupos e fases do estudo. Já os estímulos de marketing fazem parte do cenário de consumo, o que pode levar o consumidor ou não a realizar um comportamento. Ambos são combinados na predição da escolha seguinte. Além disso, esse sugere consequências do comportamento, uma vez realizado, há reforços utilitários e informativos das marcas que podem aumentar / diminuir a probabilidade de que algumas sejam adquiridas novamente.

Através do relato de cada participante e das características apontadas na fase 1 se pode confirmar que as experiências anteriores prevaleceram no momento da escolha. De forma sucinta descreveram que a marca, preço, fragrância, tradição no mercado e a utilização anteriormente à pesquisa é o mais importante, na visão dos participantes para a escolha de marcas de produtos. Percebe-se que os reforços utilitários têm maior influência na escolha subsequente do que os reforços informativos. É importante comentar que o número de alternativas não corroborou para a preferência de escolha dos participantes, o que propicia a evidência de que o histórico de compras é o principal responsável por estas escolhas e o que indica serem mais sensíveis aos atributos utilitários.

O participante 3 do grupo 2 desperta atenção para as suas escolhas, pois foi o que mais apresentou variação, dessa forma se sugere um novo estudo para verificar o que pode ter ocorrido e que variáveis foram responsáveis por tal instabilidade nas preferências de escolha.

\section{Referências}

ALHADEFF, D.A. Microeconomics and human behavior: toward a new synthesis of economics and psychology. California: Univ of California Press, 1982.

BLACKWELL, R.D.; ENGEL,J.F.; MINARD, P.W. Comportamento do consumidor. Rio de Janeiro: 2005.

FOXALL, G.R. Interpreting Consumer Choice: the Behavioral Perspective Model. Routledge: New York, 1993.

FOXALL, G.R. Radical Behaviorist interpretation: generating and evaluating anaccount of consumer. Behavior Analyst, v.21, n.2, p.321-354, 1990.

FOXALL, G.R. The Behavioral perspective model of purchase and consuptiom:From consumer theory to marketing practice. $J$. Theacademy Mark. Sci., v.20, n.2, p.189-198, 1987.

KOTLER, Philip. Administração de marketing: análise, planejamento, implementação e controle. São Paulo: Atlas, 2003. 
KOTLER, P. ARMSTRONG G. Principios de marketing. São Paulo: JC Editora, 2003.

KOTLER, P.; KELLER, K.L. Administração de marketing. São Paulo: Prentice Hall, 2006.

LAS CASAS, A.L. Marketing: conceitos, exercícios, casos. São Paulo: Atlas, 1983.

McKENNA, R. Estratégias de marketing em tempos de crise. Rio de Janeiro: Campus, 1993.

OLIVEIRA-CASTRO, J.M.; FOXALL, G.R. Análise do comportamento do consumidor. Análise do comportamento: pesquisa, teoria e aplicação. São Paulo: Artmed, 2005.

SCHIFFMAN, L.G.; KANUK, L.L. Comportamento do consumidor. Rio de Janeiro: LTC, 2000.

SKINNER, G.W. Chinese society in Thailand: an analytical history. Cornell University Press, 1957.

YANI-DE-SORIANO, M.; FOXALL, G.R.; NEWMAN, A.J. The impact of the interaction of utilitarian and informational reinforcement and behavior setting scope on consumer response. Psychol. Marketing, v.30, n.2, p.148-159, 2013. 